\title{
Powder and Solvent for Endosinusial Solution Dosage Form
}

National Cancer Institute

\section{Source}

National Cancer Institute. Powder and Solvent for Endosinusial Solution Dosage Form.

NCl Thesaurus. Code C149781.

Powder and solvent intended for the preparation of an endosinusial solution by dissolving the powder in the solvent. 